\title{
Tissue Engineering for Total Meniscal Substitution: Animal Study in Sheep Model
}

\author{
ELIZAVETA KON, M.D., 1,* CATHARINA CHIARI, M.D., ${ }^{2, *}$ MAURILIO MARCACCI, M.D., \\ MARCO DELCOGLIANO, M.D., ${ }^{1}$ DONALD M. SALTER, M.D., ${ }^{3}$ IVAN MARTIN, Ph.D., ${ }^{4}$ \\ LUIGI AMBROSIO, Ph.D., ${ }^{5}$ MILENA FINI, M.D., ${ }^{1}$ MATILDE TSCHON, Ph.D., 1 \\ ENRICO TOGNANA, Ph.D., ${ }^{6}$ ROBERTO PLASENZOTTI, D.V.M., 7 \\ and STEFAN NEHRER, M.D., Ph.D. ${ }^{8}$
}

\begin{abstract}
Objective: The aim of the study was to investigate the use of a novel hyaluronic acid/polycaprolactone material for meniscal tissue engineering and to evaluate the tissue regeneration after the augmentation of the implant with expanded autologous chondrocytes. Two different surgical implantation techniques in a sheep model were evaluated. Methods: Twenty-four skeletally mature sheep were treated with total medial meniscus replacements, while two meniscectomies served as empty controls. The animals were divided into two groups: cell-free scaffold and scaffold seeded with autologous chondrocytes. Two different surgical techniques were compared: in 12 animals, the implant was sutured to the capsule and to the meniscal ligament; in the other 12 animals, also a transtibial fixation of the horns was used. The animals were euthanized after 4 months. The specimens were assessed by gross inspection and histology. Results: All implants showed excellent capsular ingrowth at the periphery. Macroscopically, no difference was observed between cell-seeded and cell-free groups. Better implant appearance and integrity was observed in the group without transosseous horns fixation. Using the latter implantation technique, lower joint degeneration was observed in the cell-seeded group with respect to cell-free implants. The histological analysis indicated cellular infiltration and vascularization throughout the implanted constructs. Cartilaginous tissue formation was significantly more frequent in the cell-seeded constructs. Conclusion: The current study supports the potential of a novel HYAFF/polycaprolactone scaffold for total meniscal substitution. Seeding of the scaffolds with autologous chondrocytes provides some benefit in the extent of fibrocartilaginous tissue repair.
\end{abstract}

\section{INTRODUCTION}

$\mathbf{L}$ ESIONS OF THE MENISCUS are frequently observed in orthopedic practice. Injury or loss of meniscal tissue potentially leads to pain, knee dysfunction, and osteoarthritis at long term. ${ }^{1-3}$ Healing of ruptured menisci is usually limited to the vascularized areas in the outer onethird of the meniscus. ${ }^{4,5}$ Studies have demonstrated that

\footnotetext{
${ }^{1}$ Rizzoli Orthopedic Institute, Bologna, Italy.

${ }^{2}$ Department of Orthopaedics, Medical University of Vienna, Vienna, Austria.

${ }^{3}$ Department of Pathology, College of Medicine and Veterinary Medicine, University of Edinburgh, Edinburgh, United Kingdom.

${ }^{4}$ Departments of Surgery and of Research, University Hospital Basel, Basel, Switzerland.

${ }^{5}$ Institute of Composite and Biomedical Materials-IMCB-CNR, Naples, Italy.

${ }^{6}$ Fidia Advanced Biopolymers s.r.l., Abano Terme (PD), Italy.

${ }^{7}$ Core Unit of Biomedical Research, Medical University of Vienna, Vienna, Austria.

${ }^{8}$ Department of Regenerative Medicine, Danube University, Krems, Austria.

*These authors contributed equally to this work.
} 
healing of the knee is inversely related to the amount of meniscal tissue resected. ${ }^{6,7}$ However, a large proportion of meniscal tears observed at arthroscopy remain irreparable, and partial, subtotal, or even total meniscectomy is often necessary, regardless of the recognized consequence. In cases of extensive destruction and complete loss of the meniscus, only two methods are available in clinical practice today for meniscal substitution: allograft transplantation and collagen meniscus implantation. In cases of extensive destruction with a meniscal rim left intact, the collagen meniscus implant (CMI) is used for partial meniscus substitution. Complete loss of the meniscus can only be treated by allograft transplantation. In properly selected patients, meniscal allografts based on various preservation techniques (fresh, fresh frozen, and cryopreserved) have been shown to heal to the capsule and relieve pain. However, their long-term success, durability, safety, and chondroprotective effects are still uncertain. 8,9

The CMI (ReGen Biologics, Franklin Lakes, NJ) is the only scaffold used so far in a clinical setting, ${ }^{10-14}$ even if CMI cannot be considered as total meniscal substitute as a residual rim of the original meniscus is necessary to fix the implant. Despite improvements in pain and selfevaluation, ${ }^{12}$ the histological and magnetic resonance imaging (MRI) results remain controversial. ${ }^{10,13,15}$

Several materials have been tested as partial meniscus substitutes in animal models. Veth et al. ${ }^{16}$ used carbon fiber for meniscus repair in dogs, with unsatisfactory results. Small intestinal submucosa (SIS) was successfully used to repair posterior vascular meniscal defects, ${ }^{17}$ but not for total substitution. Total meniscus substitution remains difficult and has been poorly described in the literature. A polyvinyl alcohol-hydrogel meniscus in rabbits showed promising results in terms of chondroprotection, but certain unresolved problems persisted, such as durability of the polymer, the fixation method, and complete tissue regeneration in a material that does not adhere to tissue. ${ }^{18,19}$ Tienen et $a .^{20}$ applied two different porous polyester urethane polymers as meniscus prostheses in dogs. Although they also showed promising results in respect of tissue formation, one of the materials (aromatic 4,4,-diphenylmethanediisocynate based) is thought to degrade into toxic products. Other porous polymer implants did not prevent cartilage degeneration or were not suitable as meniscal substitutes because of poor tissue ingrowth related to polymer degradation rate, and poor mechanical properties. $^{21-23}$

Tissue engineering has recently been proposed as a possible solution for meniscal regeneration. ${ }^{15,24-28}$ There have, however, been very few animal studies reported in the literature that have investigated the possibility of using cells in a partial or total meniscal substitute. ${ }^{15,24}$ Walsh et $a l^{25}{ }^{25}$ used a collagenous sponge loaded with mesenchymal stem cells to heal a partial meniscus defect in rabbits and reported that the presence of cells augmented the repair process but did not prevent degenerative osteoarthritis.
Martinek et al. ${ }^{15}$ reported better macroscopic and histological results in CMI implants seeded with meniscal fibrochondrocytes in comparison to cell-free implants in sheep. However, the tissue-engineered meniscus was biomechanically unstable and the implant size reduced during the 3-month observation period. The authors suggested that an improvement in scaffold and cell seeding procedure is required before human application.

Different cell sources have also been analyzed in vitro to find the most suitable source for cell augmentation of tissue-engineered meniscus. Articular chondrocytes showed the highest capacity for generating tissues with cellular and matrix phenotypes including glycosaminoglycan expression similar to those of both the inner and outer meniscus regions. ${ }^{29}$ Moreover, cartilage harvesting from a minorly loaded joint area would be less damaging to the joint as compared to healthy meniscal tissue harvesting. The surgical technique used in animal models for total meniscal replacement has also not been highly investigated and consistent, as authors use different animal models (rabbit, $\mathrm{dog}$, and sheep) and diverse surgical techniques.

In a previous study, a new resorbable biomaterial consisting of hyaluronic acid (HYAFF; Fidia Advanced Biopolymers [FAB], Abano Terme, Italy) and polycaprolactone (PCL) was tested for total meniscal substitution in an in vivo study in sheep. Tissue integration between the joint capsule and the implant was observed with tissue formation, cellular infiltration, and vascularization. ${ }^{30}$ Our hypothesis was that the application of a tissue engineering approach, using cells seeded onto this scaffold, would offer some benefits in patients submitted to total meniscectomy by increasing the biological response and remodeling processes. Therefore, the aim of the current study was to investigate the feasibility of using this novel material for meniscal tissue engineering and to evaluate the tissue regeneration after the augmentation of the implant with autologous articular chondrocytes expanded ex vivo. The secondary aim was to evaluate two different surgical scaffold implantation techniques in an animal model: suture to the capsule and to the meniscal ligament, with or without transtibial fixation of the horns.

\section{MATERIALS AND METHODS}

\section{Study design}

All procedures were approved by the Technical, Scientific, and Ethics Committees of both experimentation centers (Rizzoli Orthopaedic Institute and Vienna University) and by the Italian and Austrian Ministries of Health. The study was performed by strictly following National Laws on animal experiments (Law by Decree 116/92 and TVG, BGBI No. 501/1988, 169/1999, and 136/2001).

Twenty-six skeletally mature female adult sheep, mean age 3.1 years $( \pm 1.8$ years) (13 Bergamasca-Massese, $70 \pm 5 \mathrm{~kg}$ body weight [b.w.], and 13 Austrian Stone sheep, 
$55 \pm 11 \mathrm{~kg}$ b.w.) were acquired from authorized farms, and kept in quarantine for at least 7 days before use. Under general anesthesia, animals underwent medial total meniscal meniscectomy of the right stifle joint and were divided into two groups. The cell-seeded group $(n=12)$ received total medial meniscal replacement by the implantation of a scaffold seeded with autologous chondrocytes, while in the cell-free group $(n=12)$, a meniscus was replaced by a cell-free scaffold.

In each animal group (cell seeded and cell free), two different surgical techniques of scaffold implantation were compared: in six animals of each group, the implant was sutured to the capsule and to the meniscal ligament ( $\mathrm{R}$ animals) (Fig. 1). In the other six animals of each group, the implantation was performed in the same way, but also the transtibial fixation of the horns was used (V animals) (Fig. 2).

In the cell-free group, the left stifle joints served as nonoperated joints for comparison. In the cell-seeded group, the cartilage biopsy was performed from non-weight-bearing areas of the left stifle joint to obtain the chondrocyte culture. The medial meniscus was left untouched, and these joints were used as sham controls in order to see the impact of the arthrotomy in a healthy joint. The cells harvested from the sheep were expanded and then seeded onto the scaffold as described below. Each group had one empty control (two animals) with total medial meniscectomy left untreated. In the empty controls, medial meniscectomy was performed using the same surgical technique as described above without insertion of a meniscus device.

All sheep received an external plaster (Scotch/Soft Cast; $3 \mathrm{M}$ Health Care, St. Paul, MN) to limit motion at the operated limb for 5 days, as described by Dorotka et al. ${ }^{31}$ Free movement within the cage was permitted immediately after surgery. After 2 weeks, the stitches were removed and the sheep were returned to the external stabling fields until the end of the experiment (16 weeks).

\section{Surgical procedure}

Surgery was conducted under general anesthesia. General anesthesia was performed following a standardized protocol: premedication with $10 \mathrm{mg} / \mathrm{kg}$ ketamine i.m. (Ketavet 100; Farmaceutici Gellini SpA, Aprilia, Latina, Italy), $0.3 \mathrm{mg} / \mathrm{kg}$ xylazine i.m. (Rompun Bayer AG, Leverkusen, Germany), and $0.0125 \mathrm{mg} / \mathrm{kg}$ atropine sulfate s.c.; induction with $6 \mathrm{mg} / \mathrm{kg}$ sodium thiopentone i.v. (2.5\%); maintenance with oxygen, $\mathrm{NO}_{2}$, and 2-3\% fluothane (Halothan; Hoechst AG, Frankfurt, Germany) under assisted ventilation (Servo Ventilator 900 D; Siemens, Munich, Germany). A blood analysis was performed from the radial vein. Antibiotics (cefalosporin $1 \mathrm{~g} /$ day for 5 days) and analgesics (ketoprofen $500 \mathrm{mg} /$ day for 3 days) were administrated postoperatively, and a veterinarian checked the animals' health.

An anteromedial arthrotomy was performed. The medial collateral ligament (MCL) was cut slightly above the joint line. This was necessary to achieve good exposure of the

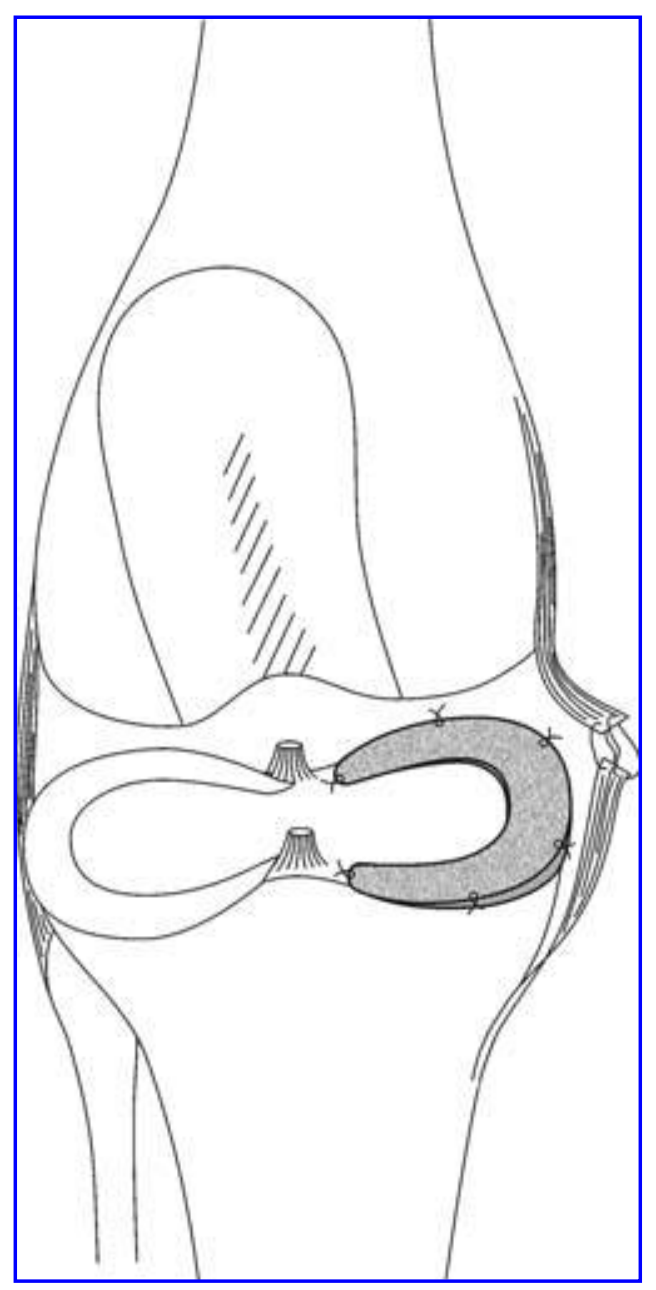

FIG. 1. Surgical technique used in R group of animals: implant was sutured to the capsule, the anterior and posterior horns of the implant being fixed to the meniscal ligaments.

posterior aspect of the joint. The meniscus was circumferentially dissected from the capsule; the posterior horn of the meniscus was exposed by flexion, external rotation, and valgus stress of the joint; the meniscus was detached at its posterior and anterior horns. No residual meniscal rim was left. In 12 sheep $(6$ cell free +6 cell seeded), the implant was sutured to the capsule at the level of the original meniscal rim, the anterior and posterior horns of the implant being fixed to the meniscal ligaments (R group, Fig. 1). In the other 12 sheep $(6$ cell free +6 cell seeded), the implantation was performed in the same way, but, additionally, two 3-mm tunnels were drilled with a guide wire from the medial tibial condyle to the footprints of the anterior and posterior meniscal horns. Two nonresorbable anchoring sutures were inserted through the implant at its horns, pulled through the bone tunnels, and tied to each other in a knot on the tibial surface (V group, Fig. 2). The capsule was closed. The MCL was reconstructed with four sutures, using resorbable sutures. The skin was closed by standard surgical techniques. 


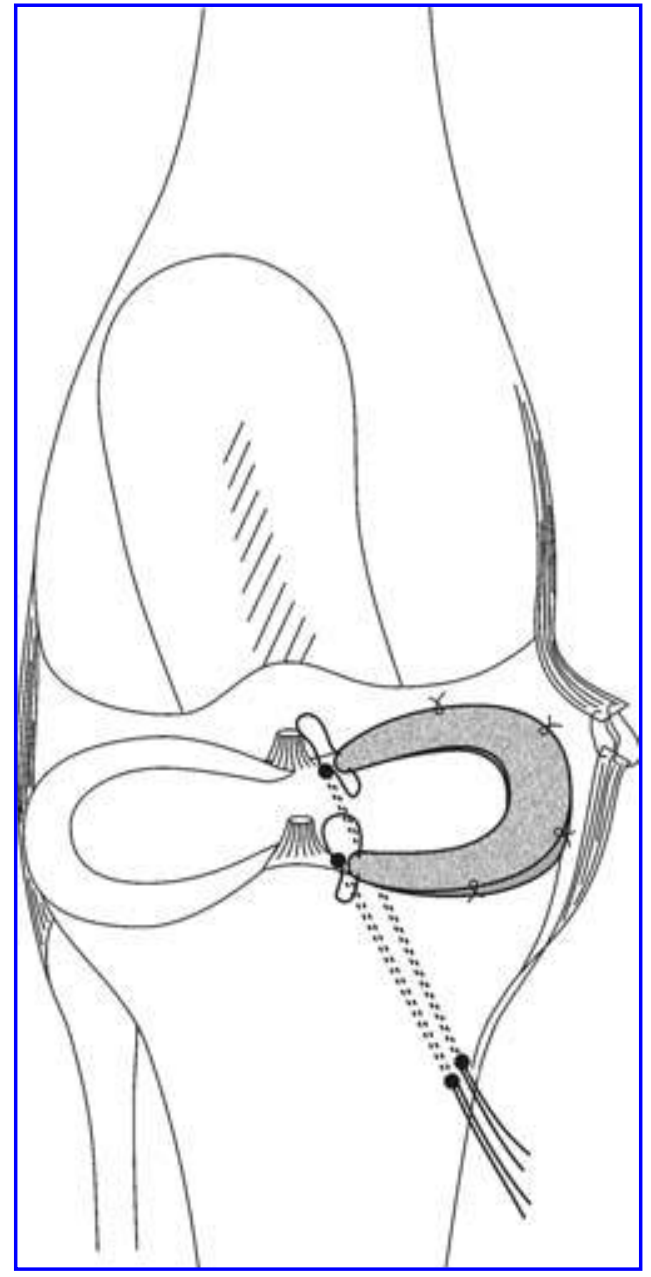

FIG. 2. Surgical technique used in V group of animals: implant was sutured to the capsule, the anterior and posterior horns of the implant fixed with nonresorbable anchoring transtibial sutures.

\section{Biomaterial and implant}

Porous scaffold preparation. The scaffold was a porous blend of polycaprolactone (PCL) and HYAFF, a class of hyaluronan-derived polymers obtained by a coupling reaction (FAB), with a pore size of $200-300 \mu \mathrm{m}$. The meniscus-like composite devices were produced by a lamination technique using molds that were designed according to original sheep menisci. Polycaprolactone (PCL) pellets of $294 \mathrm{mg} / \mathrm{mL}$ ( $M_{\mathrm{w}}=65,000$; Aldrich, St. Louis, MO) were dissolved in a tetrahydrofuran/dimethyl sulfoxide 80/ $20(\mathrm{w} / \mathrm{w})$ solution, by stirring the components at $45^{\circ} \mathrm{C}$. A mixture of salts consisting of $93.9 \%(\mathrm{w} / \mathrm{w})$ sodium chloride (with granulometry $315-400 \mu \mathrm{m}), 3.5 \% \quad(\mathrm{w} / \mathrm{w})$ sodium bicarbonate (with granulometry $140-315 \mu \mathrm{m}$ ), and $2.6 \%$ $(\mathrm{w} / \mathrm{w})$ citric acid (with granulometry inferior to $200 \mu \mathrm{m}$ ) was prepared. Successively, PCL solution and HYAFF-11 p75 HE powder (supported by FAB) at a ratio of PCL/ HYAFF 70/30 (w/w) were mixed with salts, until a homo- geneous paste was obtained. The ratio of polymers to salts was $1 / 10$. The salts increase the porosity of the structure and ensure the interconnection of pores.

The paste obtained was then poured in a meniscusshaped Teflon mold containing a polylactic acid (PLA) net. The meniscus device was augmented with circumferential PLA fibers, which protruded at the anterior and posterior horns and could be pulled through transosseous tunnels. PLA fibers were arranged in the mold, and the remaining paste was used as matrix to fill it. The samples obtained were left in air for $24 \mathrm{~h}$ and immersed in bidistilled water for 1 day. Subsequently, they were immersed in bidistilled water at $40^{\circ} \mathrm{C}$ for $5 \mathrm{~h}$ to remove the solvents. The porous scaffolds were then left in bidistilled water for a further 5 days, changing the water everyday for complete removal of salts and any residual solvents. The samples were removed from molds and immersed in an ethanol/water 70/30 (w/w) solution, followed by placement in an Edwards lyophilisator to remove the water. The porous scaffolds obtained were immersed in a $8 \mathrm{mg} / \mathrm{mL}$ hyaluronic acid solution and lyophilized again. The structures were finally sterilized through $\gamma$ radiation $(2.5 \mathrm{Mrad})$. The length of the final implants was $32 \mathrm{~mm}$, and the diameter was $22 \mathrm{~mm}$. The height of the implant at the periphery was 6 to $8 \mathrm{~mm}$.

The final implants were analyzed by scanning electron microscopy (Leica, Solms, Germany), microtomography (SkyScan, Kontich, Belgium), and microCT.

The in vivo degradation time can be estimated on the basis of the behavior of the individual components. PCL degrades slowly by hydrolytic chain scission of the ester linkage. ${ }^{32}$ PCL loses its in vivo molecular weight slowly (up to 12 months, depending on the polymer composition), but loses its mechanical stability much earlier (between 12 and 16 weeks). ${ }^{33}$ HYAFF- $11^{\circledR}$ degrades by deesterification in 3-4 months in vivo. ${ }^{34}$

\section{Implant assessment}

Porous scaffolds were cut along the cross section and subjected to analysis for evaluating the pore average size by a scanning electron microscope (Leica, 420). The material investigated was characterized by highly interconnected pores with an average pore size of $250 \mu \mathrm{m}$ (Fig. 3A, B). Moreover, the porous scaffolds displayed a large surface area, which should support cell attachment and tissue ingrowth.

Porous scaffolds, sheep medial menisci, and meniscus devices prepared were analyzed by a SkScan microtomograph allowing a spatial resolution of $5 \mu \mathrm{m}$ corresponding to near $1 \times 10^{-7}$ cubic $\mathrm{mm}$ voxel size, making a nondestructive three-dimensional (3D) reconstruction of the porous samples inner structure from two-dimensional X-ray shadow projections (Fig. 3C, D). Several parameters obtained from the microtomographic analysis, including total volume $\left(V_{\text {tot }}\right)$, specific volume $(v)$, empty index $(e)$, and porosity $(P)$, were evaluated through CTAn software. The results are shown in Table 1. 


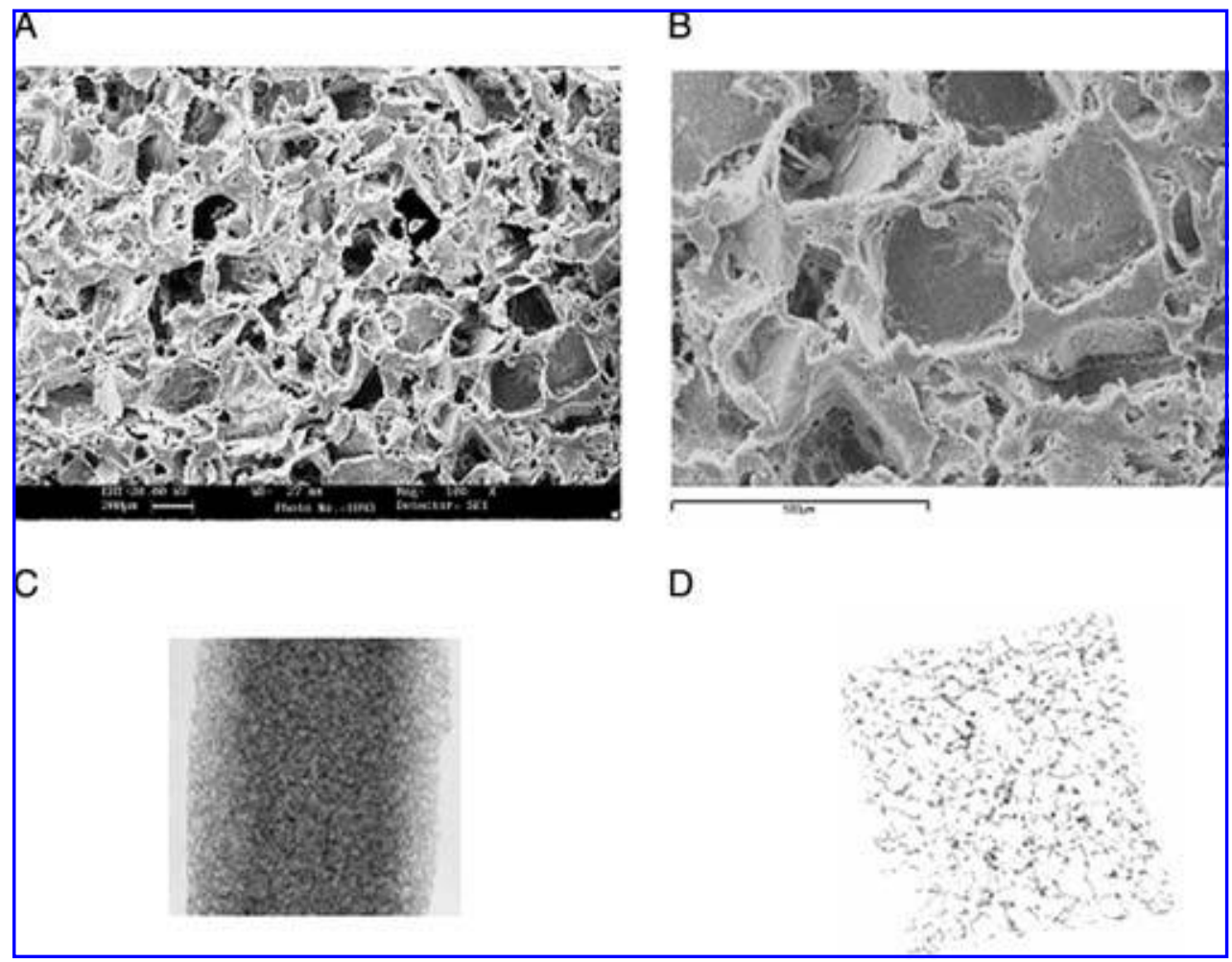

FIG. 3. Images of porous structure obtained through scanning electron microscopy analysis (A, B) and with microtomograph Skyscan $1072(\mathbf{C}, \mathbf{D})$.

MicroCT analysis was also undertaken to perform 3D reconstructions of sheep medial meniscus (Fig. 4A). Using data from these 3D reconstructions and Materialise MIMICS software, 3D CAD drawings have been designed and used to produce the appropriate molds (Fig. 4B).

\section{Cell-scaffold construct preparation}

Cartilage biopsies were taken from the left stifle joints. An anteromedial arthrotomy was performed, and cartilage was harvested from the non-weight-bearing areas of the trochlea. The cartilage biopsies were put into sterile $50 \mathrm{~mL}$ tubes with nutrient medium and sent to FAB for the cell seeding procedure. Chondrocytes were isolated by sequential enzymatic digestions. Cartilage was incubated for 30 min with $0.1 \%$ hyaluronidase (Sigma, St. Louis, MO),

Table 1. Values of Parameters Obtained Through Tomographic Analysis Performed on Porous Scaffolds

\begin{tabular}{lr}
\hline$V_{\text {tot }}\left(\mathrm{mm}^{3}\right)$ & 22.36 \\
$V_{\mathrm{s}}\left(\mathrm{mm}^{3}\right)$ & 7.12 \\
$V_{\mathrm{v}}\left(\mathrm{mm}^{3}\right)$ & 15.24 \\
$v$ & 3.14 \\
$e$ & 2.14 \\
$P$ & 0.68 \\
\hline
\end{tabular}

$1 \mathrm{~h}$ with $0.5 \%$ pronase (Sigma), and $1 \mathrm{~h}$ with $0.2 \%$ collagenase (Sigma) at $37^{\circ} \mathrm{C}$. The isolated chondrocytes were then centrifuged for $10 \mathrm{~min}$ at $1800 \mathrm{rpm}$, and the pellet was washed twice with Dulbecco's modified Eagle's medium (DMEM) supplemented with $10 \%$ fetal calf serum (FCS; Sigma). The cells were cultured under conventional monolayer culture conditions at $37^{\circ} \mathrm{C}$ in $5 \%$ carbon dioxide. The medium was changed every 3-4 days. After the third to fourth passage, chondrocytes had uniformly acquired a fibroblastic, dedifferentiated morphology and were then dynamically seeded onto the meniscus prototype at a density of $25 \times 10^{6}$ cells $/ \mathrm{cm}^{3}$ (i.e., $40 \times 10^{6}$ cells/scaffold) in a mixed flask (50 rpm) in a volume of $100 \mathrm{~mL}$ of DMEM, supplemented with 10\% FCS (complete medium) (Fig. 5). Medium was removed $24 \mathrm{~h}$ after seeding and replaced by complete medium supplemented with $10 \mu \mathrm{g} / \mathrm{mL}$ insulin, $0.1 \mathrm{mM}$ ascorbic acid, and $1 \mathrm{ng} / \mathrm{mL}$ transforming growth factor beta 1 (TGF $\beta 1$ ). Media were changed twice a week thereafter. After 14 days of spinner flask culture, prototypes were ready for in vivo implantation.

\section{Evaluation}

Specimen preparation and gross inspection. Sixteen weeks after surgery, the sheep were euthanized under general anesthesia by endovenous administration of Tanax (Hoechst, Frankfurt am Main, Germany). A sample of 


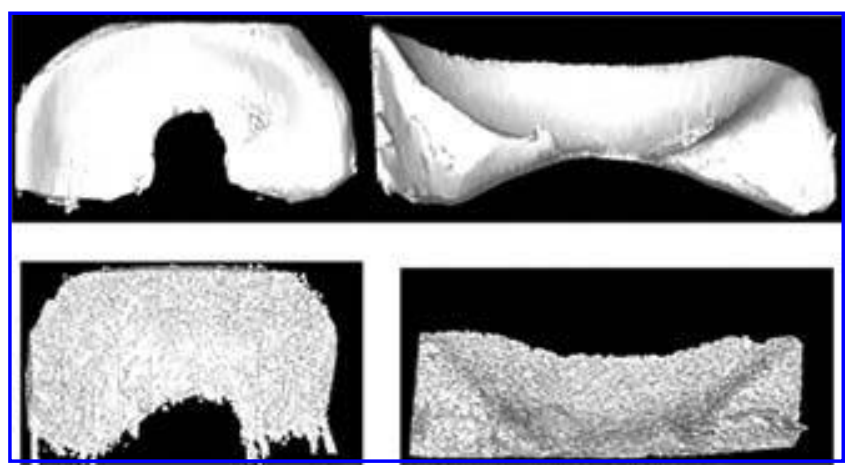

FIG. 4. 3D reconstructions of a sheep medial meniscus (A, top) and of medial meniscus device (B, bottom).

blood was taken for analysis to detect infection or allergic reactions. A radiographic examination was performed, and the joints were assessed clinically for swelling and stability. The clinical examination of ligament stability was performed under anesthesia in comparison to the contralateral joint before the resection of the joint. Under sterile conditions, the right and the left joints were opened through the previous approach, a swab for microbiological analysis and a synovial aspirate were taken, and the presence of effusion or popliteal cysts was documented. Synovial fluid was analyzed for the presence of inflammatory cells.

The joint was resected in toto, and the restoration of the MCL was inspected. Joint status was assessed using the Gross Assessment of Joint Changes Score published by Jackson et al., ${ }^{35}$ which scores 12 different areas of the joint, including the femoral and tibial cartilage, the patella, its femoral groove, the menisci, and the femoral junction. A Gross Evaluation of Meniscus Implant Score was used to assess implant outcome. ${ }^{30}$ This includes nine different categories: implant size, implant integration, implant position, horn position, implant shape, presence of tears, implant surface, tissue quality, and condition of the synovia. In this system, the minimum total score is 9 , indicating an excellent outcome, and the maximum total score is 27 points. The specimens were photographed, and then the implant was dissected from the tibia.

Histological evaluation. The meniscal implants were cut into an anterior part and a posterior part at the level of the MCL. Consecutive 3-mm slices (inner to outer) were cut to produce blocks allowing histological sections that showed inner and outer regions, superior and inferior surfaces of the potentially regenerated meniscus, and attachment to the joint capsule. Of each implant, two central and two peripheral blocks were evaluated. A synovial biopsy from the medial compartment adjacent to the meniscal implant was taken from each joint. Tissue blocks were fixed in $10 \%$ neutral-buffered formalin and processed into paraffin wax. Paraffin sections were cut at 3-4 $\mu \mathrm{m}$ and stained with (i) hematoxylin and eosin for assessment of cellular features, (ii) alcoholic toluidine blue for assessment of glycosaminoglycan content, and (iii) picro-sirius red for assessment of collagen deposition.

Sections were blindly evaluated by an experienced osteoarticular pathologist (D.M.S.). Blocks of synovium were assessed for the presence of synovial cell hyperplasia/ hypertrophy and an inflammatory cell infiltrate. Blocks of meniscal implant were assessed for the presence of residual scaffold, cellularity, foreign body response, inflammatory cell (lymphocytes, plasma cells, and neutrophils) infiltrate, blood vessel ingrowth, fibrous and cartilaginous matrix, and integration of the implant with the joint capsule. Cartilaginous matrix was identified as being present if cells in an area of tissue had a spherical/chondroid appearance and the surrounding matrix showed metachromasia in alcoholic toluidine blue-stained sections. Integration was scored as being good if there was no discontinuity between the implant and original joint capsule. Histological features were scored as being either present or absent.

For assessment of chondroprotective effects of the scaffold, sections were cut from formalin-fixed and paraffin-embedded transverse blocks through central, anterior, and posterior parts of the tibial plateau and femoral condyle. Sections were stained with hematoxylin and eosin and alcoholic toluidine blue, and scored blindly by D.M.S. using a modified Mankin grading system-Structure: Intact surface 0, Surface fissures 1, Surface fissures to mid zone 2, Surface fissures to deep zone 3, Complete loss of articular cartilage 4; Cells: Normal 0, Some hypercellularity 1, Clusters/cloning 2, Hypocellularity 3, Complete loss of articular cartilage 4; Proteoglycan staining: Normal 0, Slight reduction 1, Moderate reduction 2, Severe reduction 3 , No dye noted 4. Scores from each of the blocks from a tibial plateau or femoral condyle were averaged to provide a score for that joint. The results shown are the mean \pm SD of the average score for each group.

\section{Statistical analysis}

Statistical analysis was performed using the SPSS v.12.1 software (SPSS, Chicago, IL). Assessments were made in the absence of knowledge of whether implants were seeded or unseeded. Subsequently, results were tabulated against the nature of the implant, that is, seeded or unseeded in both $\mathrm{R}$ and $\mathrm{V}$ groups (Student's $t$ test). Univariate ANOVA with Tukey's post hoc test was used to compare data among all groups. Data were considered significant with $p<0.05$.

\section{RESULTS}

\section{Engineered graft characterization}

Stirring of the cell suspension in the mixed flask, where the meniscus-shaped scaffold was fixed, resulted in a cell distribution predominantly at the edges and at the periphery 


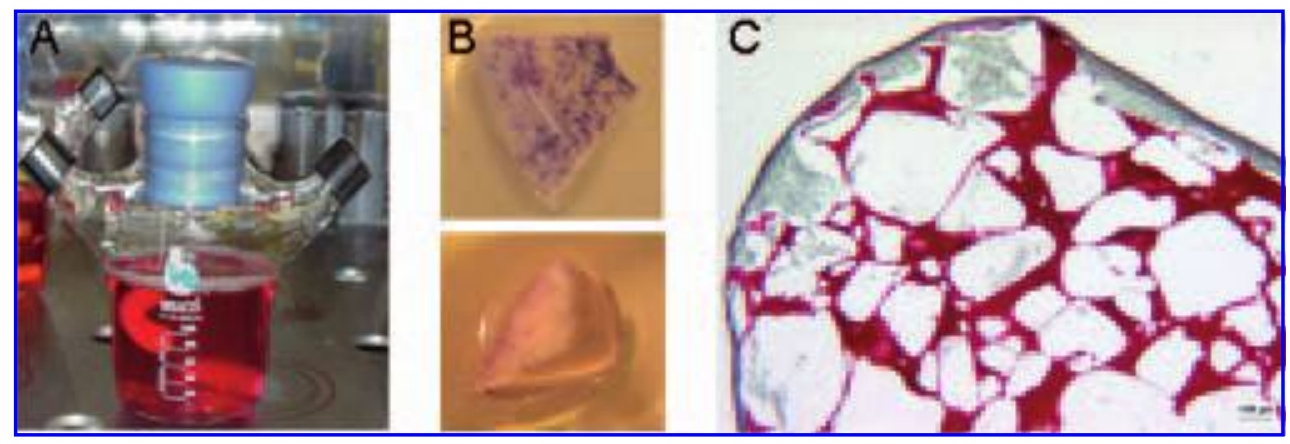

FIG. 5. (A) Seeding and culture of sheep articular chondrocytes in a meniscus-shaped brain factor 1 (BF-1) scaffold in a mixed flask under continuous stirring. (B) MTT staining after 1 day of culture in the mixed flask. The top picture is a view of the top surface of the scaffold, and the bottom picture is a representative cross section. Violet dots correspond to areas stained with MTT and indicate the presence of metabolically active cells. (C) Safranin-O staining of a construct cross section after 14 days of culture in mixed flask. Scaffold network is strongly stained in dark red, whereas the formed tissue, predominantly present at the scaffold edges, is negatively stained.

of the scaffold as assessed by MTT staining 1 day after the beginning of cell seeding (Fig. 3). After a total of 14 days of culture, cells and extracellular matrix were still confined at the scaffold surface (Fig. 5). Sulfated glycosaminoglycans (GAG) staining was not evident in the extracellular matrix that had accumulated after 14 days. This was in agreement with low measured GAG amounts (average GAG/DNA: $4.5 \pm 0.9 \mu \mathrm{g} / \mu \mathrm{g}$ ) and may be explained by the relatively low initial density of cells achieved after seeding.

\section{Clinical assessment}

All animals tolerated surgery well and survived the postsurgical period. When dissecting the knees, one animal belonging to the R group (cell seeded, R13) showed signs of severe osteoarthritis in both implanted and contralateral sham control knee. Therefore, this sheep was excluded from the postexplant evaluation. For the remaining sheep, gait was normal without limp. All joints were stable. No differences in gait and joint stability were found between left nonoperated limbs and the limbs where cartilage harvesting was performed (sham controls).

All sheep showed soft tissue swelling on the medial aspect of the operated joints. A mild effusion in the form of a clear synovial fluid was detected in nine joints (four cell free, three cell seeded, one sham control, and one nonoperated control). There were no signs of synovitis. Comparison of postoperative and preoperative radiographs revealed no signs of fracture.

\section{Implant gross assessment}

The results are summarized in Table $2 \mathrm{~A}$ and $\mathrm{B}$. Better evaluation scores were observed in $\mathrm{R}$ group respect to $\mathrm{V}$ group, where transosseous sutures were used but no significant differences were detected among groups. While pooling data of $\mathrm{R}$ and $\mathrm{V}$ sheep, no statistically significant difference was observed between cell-seeded and cell-free groups: the mean meniscus score was 20 (cell seeded and cell free).

Figures 6 and 7 illustrate macroscopic appearance of meniscal implant in different groups. All implants showed excellent capsular ingrowth at the periphery. In fact, the integration was complete in 11 cases, and partial in the others. The implant was dislocated in five cases (two cell free and three cell seeded). All dislocations were noted in the $\mathrm{V}$ group where the transtibial fixation of the horns was used. The anterior horns were anatomically positioned and firmly attached in all cases except for two joints. A slight extrusion of the implants at the periphery and wrinkling in the posterior region were frequently observed, probably causing mechanical problems and the detachment of the horns in the posterior aspect of the joint space, especially

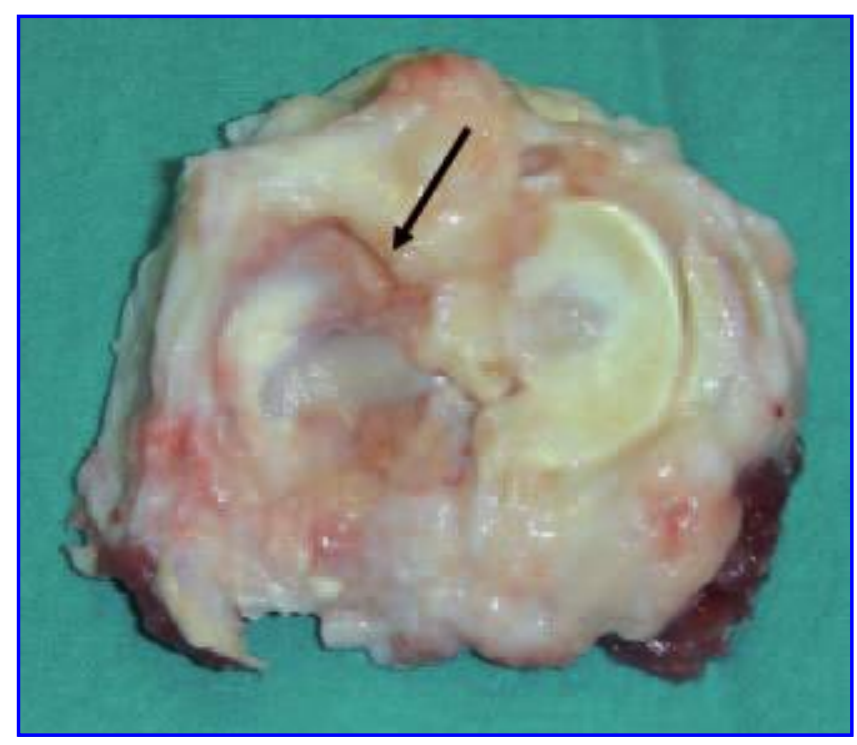

FIG. 6. Macroscopic appearance of meniscal implant in cellfree group. 
Table 2A. Gross Evaluation of the Meniscus Implant Score in R Animals (Min. 9-Max. 24 Points)

\begin{tabular}{|c|c|c|c|c|c|c|c|c|c|c|c|}
\hline & \multicolumn{6}{|c|}{ Cell free } & \multicolumn{5}{|c|}{ Cell seeded } \\
\hline & $R 23$ & $R 9$ & $R 10$ & $R 11$ & $R 12$ & $R 14$ & $R 24$ & $R 25$ & $R 26$ & $R 27$ & $R 28$ \\
\hline Integration & 3 & 3 & 2 & 3 & 2 & 3 & 2 & 2 & 3 & 2 & 3 \\
\hline Implant position & 2 & 3 & 3 & 3 & 2 & 2 & 2 & 2 & 3 & 2 & 3 \\
\hline Horn position & 2 & 3 & 2 & 3 & 2 & 3 & 2 & 2 & 3 & 2 & 3 \\
\hline Shape & 2 & 3 & 2 & 3 & 2 & 3 & 2 & 2 & 3 & 2 & 2 \\
\hline Tears & 2 & 3 & 2 & 2 & 1 & 3 & 2 & 2 & 3 & 2 & 3 \\
\hline Surface & 3 & 3 & 3 & 3 & 3 & 3 & 3 & 3 & 3 & 3 & 3 \\
\hline Size & 3 & 3 & 3 & 3 & 2 & 3 & 2 & 2 & 3 & 2 & 3 \\
\hline Tissue & 2 & 2 & 2 & 2 & 2 & 2 & 1 & 1 & 2 & 1 & 2 \\
\hline Synovia & 2 & 3 & 2 & 3 & 3 & 3 & 1 & 2 & 2 & 2 & 3 \\
\hline Total score & 21 & 26 & 21 & 25 & 19 & 25 & 17 & 18 & 25 & 18 & 25 \\
\hline Mean score \pm SD & \multicolumn{6}{|c|}{$20.7 \pm 3.6$} & \multicolumn{5}{|c|}{$23.2 \pm 3.0$} \\
\hline
\end{tabular}

Table 2B. Gross Evaluation of the Meniscus Implant Score in V Animals (Min. 9-Max. 27 Points)

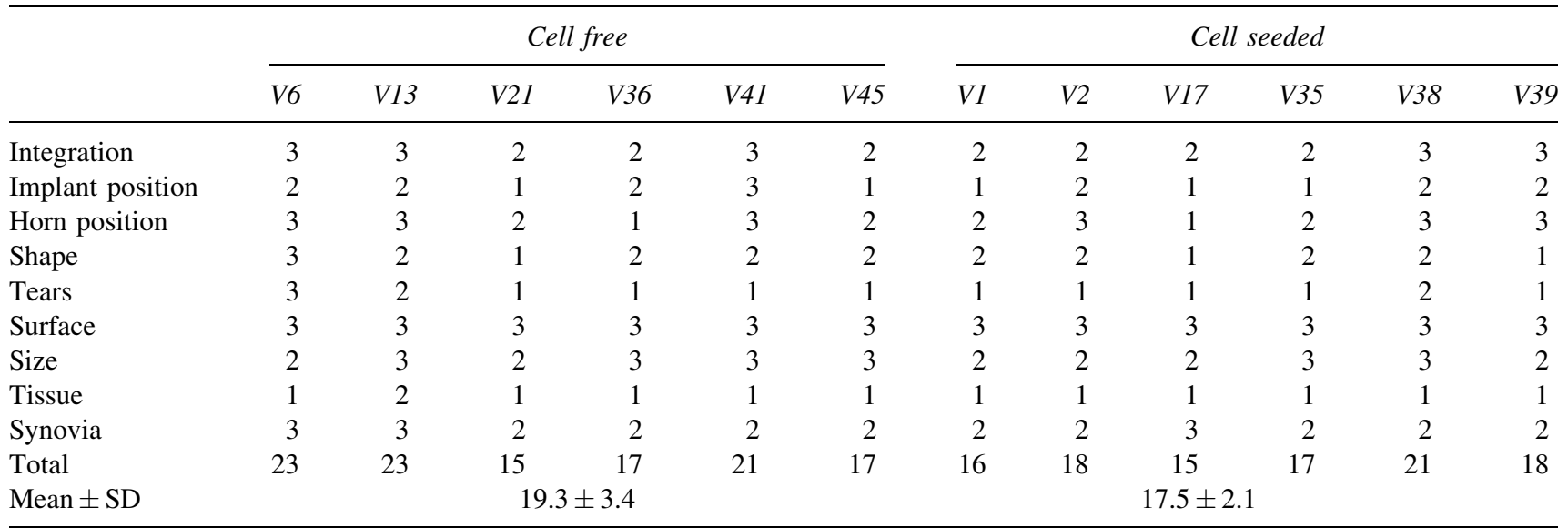

when the transtibial fixation was used. The menisci prototypes had maintained the meniscus-like or mixed shape in 21 cases; in 3 cases implants were out of shape. Ten implants (four cell free and six cell seeded) had a fullsubstance tear. Nine of those were observed in the V group. The surface of the biomaterial in all cases was completely covered with a shiny, smooth synovium-like tissue, which showed signs of blood vessel formation. Slightly hyperemic synovium was observed in the majority of the cases. No synovial hypertrophy or fibrosis was noted.

\section{Joint gross assessment}

The results are summarized in Table $3 \mathrm{~A}$ and $\mathrm{B}$. The meniscectomy controls showed a score of 14 and 13, respectively. Joint degeneration in the nonoperated joints (mean score: 1.2) and in sham controls (mean score: 1.1) was negligible. No statistically significant difference was noted between cell-seeded (5.8) and cell-free (8.0) groups when data were pooled. There was, however, significantly lower joint degeneration observed in $\mathrm{R}$ group cell-seeded implants as compared to $\mathrm{R}$ group cell-free implants $(p<0.01)$.
In the operated joints, the reconstruction of the MCL had healed in all cases. Variable degrees of cartilage damage were observed in the operated joints (min 2 and $\max 13)$. The score of sheep R13 was 18 in the operated knee and 7 in the sham-operated knee, confirming the presence of spontaneous osteoarthritis development and supporting the exclusion of this animal from the histological evaluation. The subchondral bone was exposed in four cases of cellfree group and in one sheep of cell-seeded group. The thickness of the medial joint capsule was noted in all operated joints where the MCL resuturing was performed.

\section{Histological evaluation}

There was no evidence of a significant inflammatory cell infiltrate in the synovium of joints that contained either cell-seeded or cell-free implants.

The results of the histological assessment of the meniscal implants are summarized in Table 4. Residual scaffold with an associated foreign body response consisting of a mixed giant cell and mononuclear histiocyte infiltrate was present in all the implants. In general, the foreign body reaction was florid, but focally in some of the implants, areas of 


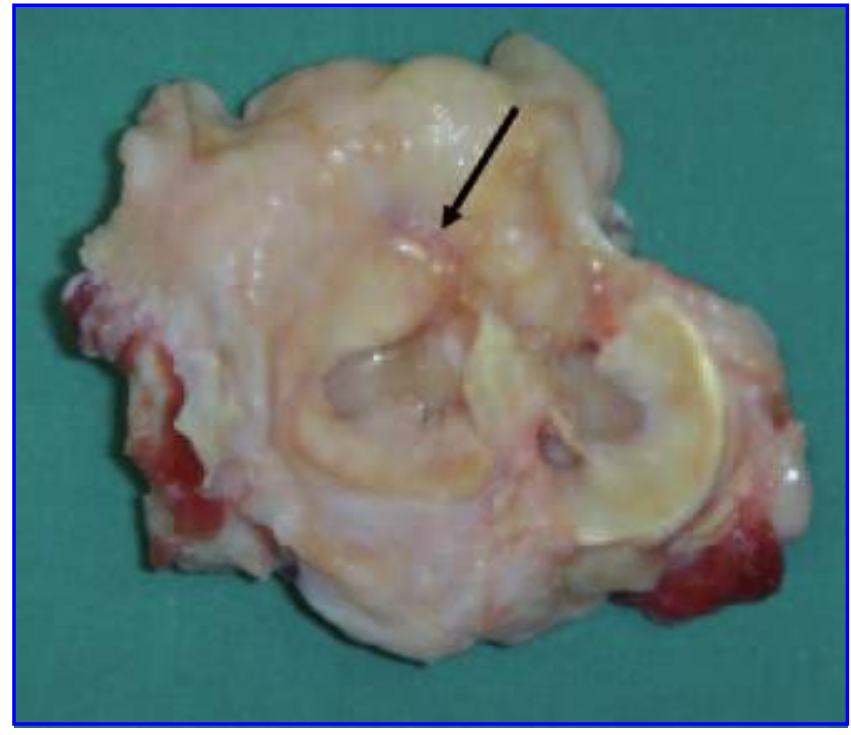

FIG. 7. Macroscopic appearance of meniscal implant in cellseeded group.

hypocellularity were evident. In addition to the foreign body reaction, all implants showed extensive vascularization with an admixture of blood vessels including small muscular arteries. Cellular tissue (Fig. 8A) was present in all of the implants to a degree that varied from area to area in the implant and did not appear to be related to cell seeding. In contrast, small foci of cartilaginous differentiation (Fig. 8B) were significantly more commonly seen in the cell-seeded constructs $(p<0.001)$. These foci of cartilage differentiation were present predominantly within fibrous tissue covering the tip of the implants, and weak metachromatic staining of tissue centrally within the implants was seen in only two of the cell-seeded implants and one unseeded implant. Scattered, small numbers of lymphocytes and plasma cells were present in both cell-seeded and unseeded implants with no statistically significant difference. Small numbers of neutrophils were seen in only two implants, one seeded and the other unseeded.

All the implants were covered by a smooth-surfaced fibrovascular tissue of variable thickness, which was in continuity with the adjacent capsule/synovium. This surface tissue appeared to be contributing to the macroscopically assessed integration in all of the implants. Histologically, however, there appeared to be differences in the integration of the cell-seeded and unseeded implants with the capsule. In all 12 cell-free implants, there was an apparently tight integration between the implant and the capsule (Fig. 8C). However, similar appearances were only seen in seven of the cell-seeded implants. In the other five cases, the cell-seeded implants showed a split in the tissue section along the line

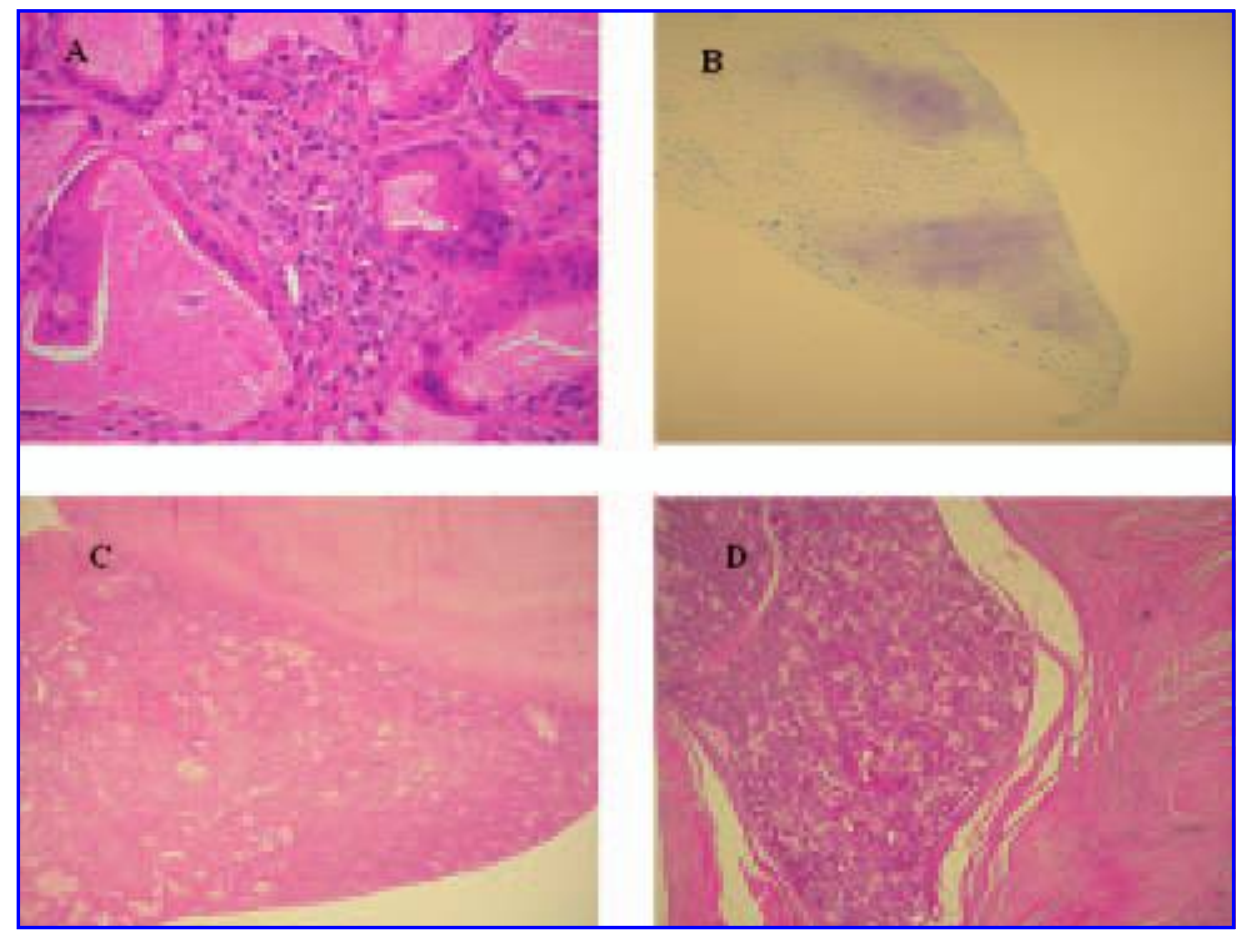

FIG. 8. Histological features of meniscus implants. A prominent foreign body reaction to residual scaffold was present in all cases. (A) HandE-stained section, $\times 40$. Foci of cartilaginous metaplasia as demonstrated by metachromatic staining were identified predominantly at the tips of implants. (B) Alcoholic toluidine blue-stained section, $\times 20$. Integration with the joint capsule was identified as being either good $(\mathbf{C})$ or poor $(\mathbf{D})$ as identified by the absence or presence of splits in the tissue between implant and host capsule. (C, D) HandE-stained sections, $\times 5$. 
Table 3A. Gross Assessment of Joint Changes Score in R Animals (Min. 48-Max. 0 Points)

\begin{tabular}{|c|c|c|c|c|c|}
\hline \multirow[b]{2}{*}{ Sheep } & \multicolumn{2}{|c|}{ Cell free } & \multicolumn{3}{|c|}{ Cell seeded } \\
\hline & Implanted knee & Nonoperated knee & Sheep & Implanted knee & Sham-operated knee \\
\hline $\mathrm{R} 23$ & 11 & 1 & R9 & 3 & 0 \\
\hline $\mathrm{R} 24$ & 10 & 2 & $\mathrm{R} 10$ & 4 & 1 \\
\hline $\mathrm{R} 25$ & 11 & 3 & $\mathrm{R} 11$ & 2 & 0 \\
\hline $\mathrm{R} 26$ & 7 & 1 & $\mathrm{R} 12$ & 6 & 1 \\
\hline $\mathrm{R} 27$ & 13 & 2 & $\mathrm{R} 14$ & 6 & 1 \\
\hline $\mathrm{R} 28$ & 4 & 1 & & & \\
\hline Mean \pm SD & $9.3 \pm 3.2$ & $1.6 \pm 0.8$ & & $4.2 \pm 1.7$ & $0.6 \pm 0.5$ \\
\hline
\end{tabular}

Table 3B. Gross Assessment of Joint Changes Score in V Animals (Min. 48-Max. 0 Points)

\begin{tabular}{|c|c|c|c|c|c|}
\hline \multirow[b]{2}{*}{ Sheep } & \multicolumn{2}{|c|}{ Cell free } & \multicolumn{3}{|c|}{ Cell seeded } \\
\hline & Implanted knee & Nonoperated knee & Sheep & Implanted knee & Sham-operated knee \\
\hline V6 & 6 & 3 & V1 & 7 & 1 \\
\hline V13 & 6 & 0 & $\mathrm{~V} 2$ & 9 & 1 \\
\hline V21 & 9 & 0 & V17 & 8 & 0 \\
\hline V36 & 8 & 0 & V35 & 9 & 3 \\
\hline V41 & 6 & 2 & V38 & 7 & 3 \\
\hline V45 & 6 & 0 & V39 & 5 & 1 \\
\hline Mean \pm SD & $6.8 \pm 1.3$ & $0.8 \pm 1.3$ & & $7.5 \pm 1.5$ & $1.2 \pm 1.2$ \\
\hline
\end{tabular}

where the implant met the capsule (Fig. 8D), or, in some instances, a flattened cystic-like space was present.

\section{Mankin scores}

The results are shown in Table 5. The articular cartilage in each of the groups of sheep showed evidence of osteo-

Table 4. Histological Features of Implants

\begin{tabular}{|c|c|c|c|c|c|c|}
\hline & \multicolumn{6}{|c|}{ Implant } \\
\hline & \multicolumn{3}{|c|}{ Cell free } & \multicolumn{3}{|c|}{ Cell seeded } \\
\hline & Total & $V$ & $R$ & Total & $V$ & $R$ \\
\hline Residual scaffold & 12 & 6 & 6 & 11 & 6 & 5 \\
\hline Foreign body reaction & 12 & 6 & 6 & 11 & 6 & 5 \\
\hline Hypocellular areas & 10 & 4 & 6 & 9 & 4 & 5 \\
\hline Blood vessels & 12 & 6 & 6 & 11 & 6 & 5 \\
\hline Fibrosis & 12 & 6 & 6 & 11 & 6 & 5 \\
\hline \multicolumn{7}{|l|}{ Cartilage metaplasia } \\
\hline Tip & 1 & 1 & 0 & 8 & 4 & 4 \\
\hline Central & 2 & 0 & 2 & 1 & 1 & 0 \\
\hline \multicolumn{7}{|l|}{ Integration } \\
\hline Good & 12 & 6 & 6 & 7 & 5 & 2 \\
\hline Poor & 0 & 0 & 0 & 5 & 1 & 4 \\
\hline \multicolumn{7}{|l|}{ Inflammatory infiltrate } \\
\hline Lymphocytes & 9 & 3 & 6 & 10 & 5 & 5 \\
\hline Plasma cells & 5 & 0 & 5 & 7 & 2 & 5 \\
\hline Neutrophils & 1 & 1 & 0 & 1 & 1 & 0 \\
\hline
\end{tabular}

The table shows the number of implants with each of the described histological features. V: Vienese sheep; R: Rizolli sheep. arthritic changes. In general, the histological changes of osteoarthritis were more severe on the tibial plateau than on the femoral condyles for both the $\mathrm{R}$ group and the $\mathrm{V}$ group. There was no significant difference in the Mankin scores when cell-seeded and non-cell-seeded implants were compared in either group. Mankin scores in treated sheep were not better than those of control sheep (tibial plateaux $4.5+1.44$; femoral condyles $3.8+1.9$ ).

\section{DISCUSSION}

Experimental studies concerning synthetic devices made of polyurethane, ${ }^{36,37}$ polytetrafluoroethylene, ${ }^{38}$ and polyester carbon ${ }^{39}$ as possible alternatives to meniscus allografts have yielded unsatisfactory results in terms of biocompatibility, material properties, and chondroprotection. In a dog model, the resorbable bovine collagen scaffold developed by Stone et al. ${ }^{40}$ for regeneration of meniscal tissue showed host tissue ingrowth and formation of fibrocartilage resembling a normal canine meniscus after 9 and 12 months. ${ }^{12} \mathrm{~A}$ clinical trial concerning CMI revealed encouraging results, ${ }^{10,11,13,14}$ but long-term, histological and MRI results are controversial and evidence of chondroprotection is still pending. In contrast to the present study, the CMI is used for partial meniscal substitution because a residual rim of the original meniscus is necessary to fix the CMI, which makes the comparison of our results difficult.

In the current study, we have investigated the feasibility of using a new resorbable biomaterial consisting of 
Table 5. Mankin Scores

\begin{tabular}{lccccc}
\hline & \multicolumn{2}{c}{$V$ group } & & \multicolumn{2}{c}{$R$ group } \\
\cline { 2 - 3 } \cline { 6 - 6 } & $\begin{array}{c}\text { Tibial } \\
\text { plateaux }\end{array}$ & $\begin{array}{c}\text { Femoral } \\
\text { condyles }\end{array}$ & & $\begin{array}{c}\text { Tibial } \\
\text { plateaux }\end{array}$ & $\begin{array}{c}\text { Femoral } \\
\text { condyles }\end{array}$ \\
\hline Cell free & $7.0+1.0$ & $3.2+1.2$ & & $5.7+2.4$ & $3.8+1.1$ \\
Cell seeded & $6.9+1.0$ & $3.8+1.2$ & & $6.3+3.4$ & $3.7+2.9$ \\
\hline
\end{tabular}

Results are given as mean \pm SD.

hyaluronic acid and polycaprolactone for total meniscal substitution in a sheep model with two different surgical scaffold implantation techniques. Previously, we tested the feasibility of hyaluronic acid and polycaprolactone (PCL) scaffold for total meniscal replacement. ${ }^{30}$ We also explored whether seeding the scaffold with autologous articular chondrocytes was beneficial for meniscal regeneration. Promising results were obtained by culturing autologous and allogenic chondrocytes on a Vycril mesh scaffold in the treatment of meniscal tears in pigs. ${ }^{24,27}$ Therefore, the aim of the study was to assess whether there was an advantage to using chondrocyte-seeded scaffolds. Autologous chondrocytes were used as we have previously demonstrated that, both in vitro and following ectopic implantation, expanded articular chondrocytes were superior to meniscal cells, synovial cells, or fat pad cells in their capacity to reach phenotypes typical of the inner and outer meniscus regions. ${ }^{29}$ Moreover, it has recently been established that the phenotype of articular chondrocytes may adapt upon exposure to specific regimes of physical forces, thereby generating tissue structures resembling some aspects of the complex structure and function of native meniscus. ${ }^{41}$ The choice was also influenced by the fact that harvesting articular cartilage from a minorly loaded joint area would be less damaging than harvesting part of healthy meniscus or little meniscal tissue probably remained after meniscectomy. Destroyed meniscus tissue that is removed during resection cannot be considered a healthy tissue for cell isolation.

Different fixation techniques are used for total and partial meniscal transplantation in clinical practice. For total allograft transplantation, rigid horn fixation with bone blocks is usually used, even if some authors have proposed less rigid and more physiological suturing technique. ${ }^{42}$ Although the issue of the fixation technique in humans is extensively studied, ${ }^{43}$ there are no studies comparing different techniques in animal model. In sheep models, the meniscus transplant horns are generally fixed with transosseous sutures. ${ }^{9,15,20,21,23}$ Considering that most of the animal studies reports high incidence of implant lesions at longer follow-up, ${ }^{9,15,23}$ we have decided to compare two different implant fixation techniques to determine a most suitable animal model for total meniscal substitution. The degree of damage seen in the meniscal implants at the completion of our study appears related to the implant fixation technique used. We have used two different fixation techniques allowing comparison between transtibial horn fixation with less rigid and more physiological fixation to the joint capsule. The general joint stability was not compromised in both groups. A higher incidence of tears and implant dislocations and worse implant and joint appearances was observed in cases where transtibial, rigid fixation of the horns was utilized ( $\mathrm{V}$ animal group). It is likely that a too rigid horn fixation in this weight-bearing large animal model does not allow for physiological movement of the meniscal horn, and resulted in overly high mechanical stresses on the implant leading to a higher incidence of graft tears. Similar results were reported by Kelly et al., ${ }^{9}$ who observed complete radial tears in all meniscal implants with rigid horn fixation at 12-month follow-up. This can be not predictable to utilize in humans, but it appears likely that the less-rigid fixation technique is preferable for total meniscal substitution in a sheep model.

A high incidence of implant tears and clefts, especially in cases with a transtibial rigid fixation of the horns, was detected, indicating that the mechanical properties of the scaffold were probably not sufficient in the current model. As such, the biomechanical properties of the material need to be improved for future experimentation, possibly by insertion of a stronger resorbable net inside the scaffold. Whether similar problems encountered in this sheep model, such as implant tears, would be encountered in the human clinical setting is less clear. Although sheep were immobilized in cast, full weight bearing cannot be completely avoided in a sheep model, ${ }^{44}$ whereas controlled rehabilitation with limited weight bearing and range of motion in humans may reduce these problems.

The implants appeared to be well tolerated immunologically by the sheep with no evidence macroscopically or microscopically of a significant synovitis or lymphoplasmacytic infiltrate. There was, however, a prominent foreign body giant cell response to the implant, presumably part of the physiological resorption process, ${ }^{34,45}$ which was similar in cell-seeded and cell-free constructs. Reaction to foreign material may be nonimmune or elicit an immune response with memory. The intense, predominantly macrophage and giant cell infiltrate into the scaffolds used in the current study is suggestive of a foreign body response without an immune component. However, it has been shown recently that the extent of cellular infiltration may not be an indicator of a potentially important immunological response. Porcine small intestinal submucosa (SIS) has been used as a scaffold for the treatment of large meniscal defects in dogs with some degree of promise. ${ }^{17}$ Histological evaluation shows little evidence of an inflammatory cell infiltrate in association with SIS scaffolds 12 weeks to 1 year following implantation. Although this may suggest a lack of an immunological response, it is becoming clear that SIS graft recipients do amount a helper $\mathrm{T}$ type 2-restricted immune response. ${ }^{46}$ Nevertheless, this is not associated with graft rejection. In the case of SIS, the most likely cause of 
this immune response is the presence of trace amounts of porcine DNA. ${ }^{47}$ Although xenogeneic material is not used in the current study and infiltration of the scaffolds by lymphocytes and plasma cells is limited, the possibility of an immunological response that may contribute to graft destruction cannot be excluded.

Histological analysis of the implant material confirmed the gross findings of tissue formation within and upon the implant with bonding to the capsule. The tissue ingrowth consisted of a fibrovascular connective tissue with a foreign body response to the implant material. Collagen appeared as a fine fibrillar network without orientation. Blood vessels were present throughout the implants without suggestion of formation of vascular and avascular areas as might be expected in normal menisci. Our findings are similar to those achieved with 3-month samples of the CMI dog model, where immature vascular connective tissue with fibroblasts, numerous capillaries, and a fine fibrillar matrix were seen. ${ }^{12}$ The impact of the giant cell reaction is difficult to estimate. Neither the synovial biopsies nor the smears revealed acute inflammatory cells.

Although no significant difference was shown between cell-seeded and cell-free implants at 4-month follow-up macroscopically, histological analysis did demonstrate deposition of a cartilaginous matrix only in cell-seeded implants, which may become more evident following longer observation. As the matrix is seen predominantly in the cell-seeded constructs, it is likely that the implanted cells are involved in its production. Moreover, the distribution of the cartilaginous matrix at the edges and the tip of the implant is directly related to the distribution of cells and matrix in the scaffold at the time of grafting. In this regard, more homogenous and efficient seeding of the inner twothirds of the scaffold could probably improve the overall mechanical and biological properties of the implant.

The current study supports the idea that a novel hyaluronic-acid-polycaprolactone (HA-PCL) scaffold has the potential for total meniscal substitution as it is not rejected and induces tissue ingrowth. There are, however, some limitations with regard to the biological and mechanical properties of the scaffold. Less rigid and more physiologic fixation technique of total meniscus implant is considered preferable in sheep model and recommended for further animal studies. Seeding of the scaffolds with autologous articular chondrocytes provides some benefit with more fibrocartilaginous tissue being produced also at early stages of regeneration (4 months). Significant amounts of scaffold remain at 4 months associated with a foreign body reaction. It might be expected that a foreign body reaction would last as long as there is a foreign (scaffold) material present. In the presence of a brisk foreign body reaction, it is more likely that a reparative fibrous tissue will arise rather than a situation where committed tissue differentiation is seen. Follow-up of at least a year in animal model would appear to be necessary to assess how long the bio- material remains in the tissue and to what extent a foreign body inflammatory or immune response is present.

Longer-term animal studies are necessary to fully evaluate how long the scaffold material remains in situ and whether this aids or delays meniscus tissue regeneration. These further studies will also provide additional information on the role of cell augmentation in promoting fibrocartilaginous tissue regeneration in complete meniscal substitution.

\section{ACKNOWLEDGMENTS}

Dr. Giuseppe Filardo, Dr. Angela Montaperrto, Dr. Clara Montaperto, Dr. Laura Bragonzoni, and Silvia Bassini, Laboratorio di Biomeccanica, Istituti Ortopedici Rizzoli, Bologna, Italy; Dr. Gianluca Giavaresi, Servizio di Chirurgia Sperimentale, Istituti Ortopedici Rizzoli, Bologna, Italy; Dr. Ulrich Koller, Department of Orthopaedics, Medical University of Vienna, Vienna, Austria; Dr. Sylvie Miot and Dr. Anna Marsano, Departments of Surgery and of Research, University Hospital Basel, Basel, Switzerland; Dr. Antonio Gloria, Institute of Composite and Biomedical Materials-IMCB-CNR, Naples, Italy. Support: European Commission 5th Framework Program (project title: Innovative Materials and Technologies for a Bio-Engineered Meniscus Substitute; project no. GRD1-2001-40401; contract no. G5RD-CT-2002-00703).

\section{REFERENCES}

1. Fairbanks, T. Knee joint changes after meniscectomy. J Bone Joint Surg Br 30, 664-670, 1948.

2. Wyland, D.J., Guilak, F., Elliott, D.M., Setton, L.A., and Vail, T.P. Chondropathy after meniscal tear or partial meniscectomy in a canine model. J Orthop Res 20, 996-1002, 2002.

3. Cook, J.L. The current status of treatment for large meniscal defects. Clin Orthop Relat Res 435, 88-95, 2005.

4. Miller, M.D., Warner, J.J.P., and Harner, C.D. Meniscal repair. In: Fu, F.H., Harner, C.D., Vince, K.G., eds. Knee Surgery. Philadelphia, PA: Lippincott, Williams and Wilkins, 1994, pp. 325-341.

5. Arnoczky, S.P., and Warren, R.F. The microvasculature of the meniscus and its response to injury. An experimental study in the dog. Am J Sports Med 11, 131-141, 1983.

6. McDermott, I.D., and Amis, A.A. The consequences of meniscectomy. J Bone Joint Surg Br 88, 1549-1556, 2006.

7. Hede, A., Larsen, E., and Sandberg, H. The long term outcome of open total and partial meniscectomy related to the quantity and site of the meniscus removed. Int Orthop 16, 122-125, 1992.

8. Rijk, P.C. Meniscal allograft transplantation-part II: alternative treatments, effects on articular cartilage, and future directions. Arthroscopy 20, 851-859, 2004.

9. Kelly, B.T., Robertson, W., Potter, H.G., Deng, X., Turner, A.S., Lyman, S., Warren, R.F., and Rodeo, S.A. Hydrogel meniscal replacement in the sheep knee: preliminary evalu- 
ation of chondroprotective effects. Am J Sports Med 35, 4352, 2007.

10. Zaffagnini, S., Giordano, G., Vascellari, A., Bruni, D., Neri, M.P., Iacono, F., Kon, E., Presti, M.L., and Marcacci, M. Arthroscopic collagen meniscus implant results at 6 to 8 years follow up. Knee Surg Sports Traumatol Arthrosc 15, 175183, 2007.

11. Stone, K.R., Steadman, J.R., Rodkey, W.G., and Li, S.T. Regeneration of meniscal cartilage with use of a collagen scaffold. Analysis of preliminary data. J Bone Joint Surg Am 79, 1770-1777, 1997.

12. Stone, K.R., Rodkey, W.G., Webber, R., McKinney, L., and Steadman, J.R. Meniscal regeneration with copolymeric collagen scaffolds. In vitro and in vivo studies evaluated clinically, histologically, and biochemically. Am J Sports Med 20, 104-111, 1992.

13. Steadman, J.R., and Rodkey, W.G. Tissue-engineered collagen meniscus implants: 5- to 6-year feasibility study results. Arthroscopy 21, 515-525, 2005.

14. Rodkey, W.G., Steadman, J.R., and Li, S.T. A clinical study of collagen meniscus implants to restore the injured meniscus. Clin Orthop Relat Res Suppl 367, S281-S292, 1999.

15. Martinek, V., Ueblacker, P., Bräun, K., Nitschke, S., Mannhardt, R., Specht, K., Gansbacher, B., and Imhoff, A.B. Second generation of meniscus transplantation: in-vivo study with tissue engineered meniscus replacement. Arch Orthop Trauma Surg 126, 228-234, 2006.

16. Veth, R.P., Jansen, H.W., Leenslag, J.W., Pennings, A.J., Hartel, R.M., and Nielsen, H.K. Experimental meniscal lesions reconstructed with a carbon fiber-polyurethane-poly(Llactide) graft. Clin Orthop Relat Res 202, 286-293, 1986.

17. Cook, J.L., Fox, D.B., Malaviya, P., Tomlinson, J.L., Kuroki, K., Cook, C.R., and Kladakis, S. Long-term outcome for large meniscal defects treated with small intestinal submucosa in a dog model. Am J Sports Med 34, 32-42, 2006.

18. de Groot, J.H., Zijlstra, F.M., Kuipers, H.W., Pennings, A.J., Klompmaker, J., Veth, R.P., and Jansen, H.W. Meniscal tissue regeneration in porous 50/50 copoly(L-lactide/epsiloncaprolactone) implants. Biomaterials 18, 613-622, 1997.

19. Kobayashi, M., Toguchida, J., and Oka, M. Preliminary study of polyvinyl alcohol-hydrogel (PVA-H) artificial meniscus. Biomaterials 24, 639-647, 2003.

20. Tienen, T.G., Heijkants, R.G.J.C., de Groot, J.H., Schouten, A.J., Pennings, A.J., Veth, R.P.H., and Buma, P. Meniscal replacement in dogs. Tissue regeneration in two different materials with similar properties. J Biomed Mater Res B Appl Biomater 76, 389-396, 2006.

21. van Tienen, T.G., Heijkants, R.G.J.C., Buma, P., de Groot, J.H., Pennings, A.J., and Veth, R.P.H. Tissue ingrowth and degradation of two biodegradable porous polymers with different porosities and pore sizes. Biomaterials 23, 1731-1738, 2002.

22. Tienen, T.G., Heijkants, R.G.J.C., de Groot, J.H., Pennings, A.J., Schouten, A.J., Veth, R.P.H., and Buma, P. Replacement of the knee meniscus by a porous polymer implant: a study in dogs. Am J Sports Med 34, 64-71, 2006.

23. Tienen, T.G., Heijkants, R.G.J.C., Buma, P., de Groot, J.H., Pennings, A.J., and Veth, R.P.H. A porous polymer scaffold for meniscal lesion repair-a study in dogs. Biomaterials $\mathbf{2 4}$, 2541-2548, 2003.
24. Weinand, C., Peretti, G.M., Adams, S.B.J., Bonassar, L.J., Randolph, M.A., and Gill, T.J. An allogenic cell-based implant for meniscal lesions. Am J Sports Med 34, 1779-1789, 2006.

25. Walsh, C.J., Goodman, D., Caplan, A.I., and Goldberg, V.M. Meniscus regeneration in a rabbit partial meniscectomy model. Tissue Eng 5, 327-337, 1999.

26. Verdonk, P.C.M., Forsyth, R.G., Wang, J., Almqvist, K.F., Verdonk, R., Veys, E.M., and Verbruggen, G. Characterisation of human knee meniscus cell phenotype. Osteoarthritis Cartilage 13, 548-560, 2005.

27. Peretti, G.M., Gill, T.J., Xu, J., Randolph, M.A., Morse, K.R., and Zaleske, D.J. Cell-based therapy for meniscal repair: a large animal study. Am J Sports Med 32, 146-158, 2004.

28. Ibarra, C., Koski, J.A., and Warren, R.F. Tissue engineering meniscus: cells and matrix. Orthop Clin North Am 31, 411418, 2000.

29. Marsano, A., Millward-Sadler, S.J., Salter, D.M., Adesida, A., Hardingham, T., Tognana, E., Kon, E., Chiari-Grisar, C., Nehrer, S., Jakob, M., and Martin, I. Differential cartilaginous tissue formation by human synovial membrane, fat pad, meniscus cells and articular chondrocytes. Osteoarthritis Cartilage 15, 48-58, 2007.

30. Chiari, C., Koller, U., Dorotka, R., Eder, C., Plasenzotti, R., Lang, S., Ambrosio, L., Tognana, E., Kon, E., Salter, D., and Nehrer, S. A tissue engineering approach to meniscus regeneration in a sheep model. Osteoarthritis Cartilage 14, 1056-1065, 2006.

31. Dorotka, R., Bindreiter, U., Macfelda, K., Windberger, U., and Nehrer, S. Marrow stimulation and chondrocyte transplantation using a collagen matrix for cartilage repair. Osteoarthritis Cartilage 13, 655-664, 2005.

32. Kweon, H., Yoo, M.K., Park, I.K., Kim, T.H., Lee, H.C., Lee, H., Oh, J., Akaike, T., and Cho, C.S. A novel degradable polycaprolactone networks for tissue engineering. Biomaterials 24, 801-808, 2003.

33. Pitt, C.G., Gratzl, M.M., Kimmel, G.L., Surles, J., and Schindler, A. Aliphatic polyesters II. The degradation of poly (D,L-lactide), poly (epsilon-caprolactone), and their copolymers in vivo. Biomaterials 2, 215-220, 1981.

34. Campoccia, D., Doherty, P., Radice, M., Brun, P., Abatangelo, G., and Williams, D.F. Semisynthetic resorbable materials from hyaluronan esterification. Biomaterials 19, 2101-2127, 1998.

35. Jackson, D.W., McDevitt, C.A., Simon, T.M., Arnoczky, S.P., Atwell, E.A., and Silvino, N.J. Meniscal transplantation using fresh and cryopreserved allografts. An experimental study in goats. Am J Sports Med 20, 644-656, 1992.

36. Sommerlath, K., and Gillquist, J. The effect of a meniscal prosthesis on knee biomechanics and cartilage. An experimental study in rabbits. Am J Sports Med 20, 73-81, 1992.

37. Klompmaker, J., Veth, R.P., Jansen, H.W., Nielsen, H.K., de Groot, J.H., and Pennings, A.J. Meniscal replacement using a porous polymer prosthesis: a preliminary study in the dog. Biomaterials 17, 1169-1175, 1996.

38. Toyonaga, T., Uezaki, N., and Chikama, H. Substitute meniscus of Teflon-net for the knee joint of dogs. Clin Orthop Relat Res 179, 291-297, 1983.

39. Wood, D., Minns, R., and Strover, A. Replacement of the rabbit medial meniscus with a polyester-carbon implant. Biomaterials 11, 13-16, 1990. 
40. Stone, K.R., Rodkey, W.G., Webber, R.J., McKinney, L., and Steadman, J.R. Future directions. Collagen-based prostheses for meniscal regeneration. Clin Orthop Relat Res 252, 129135, 1990.

41. Marsano, A., Wendt, D., Raiteri, R., Gottardi, R., Stolz, M., Wirz, D., Daniels, A.U., Salter, D., Jakob, M., Quinn, T.M., and Martin, I. Use of hydrodynamic forces to engineer cartilaginous tissues resembling the non-uniform structure and function of meniscus. Biomaterials 27, 5927-5934, 2006.

42. Verdonk, P.C.M., Demurie, A., Almqvist, K.F., Veys, E.M., Verbruggen, G., and Verdonk, R. Transplantation of viable meniscal allograft. Survivorship analysis and clinical outcome of one hundred cases. J Bone Joint Surg Am 87, 715-724, 2005.

43. McDermott, I.D., Richards, S.W., Hallam, P., Tavares, S., Lavelle, J.R., and Amis, A.A. A biomechanical study of four different meniscal repair systems, comparing pull-out strengths and gapping under cyclic loading. Knee Surg Sports Traumatol Arthrosc 11, 23-29, 2003.

44. Martini, L., Fini, M., Giavaresi, G., and Giardino, R. Sheep model in orthopedic research: a literature review. Comp Med 51, 292-299, 2001.

45. Sung, H., Meredith, C., Johnson, C., and Galis, Z.S. The effect of scaffold degradation rate on three-dimensional cell growth and angiogenesis. Biomaterials 25, 5735-5742, 2004.

46. Ansaloni, L., Cambrini, P., Catena, F., Di Saverio, S., Gagliardi, S., Gazzotti, F., Hodde, J.P., Metzger, D.W., D'Alessandro, L., and Pinna, A.D. Immune response to small intestinal submucosa (surgisis) implant in humans: preliminary observations. J Invest Surg 20, 237-241, 2007.

47. Zheng, M.H., Chen, J., Kirilak, Y., Willers, C., Xu, J., and Wood, D. Porcine small intestine submucosa (SIS) is not an acellular collagenous matrix and contains porcine DNA: possible implications in human implantation. J Biomed Mater Res B Appl Biomater 73, 61-67, 2005.

Address reprint requests to: Elizaveta Kon, M.D. Laboratorio di Biomeccanica Istituti Ortopedici Rizzoli Via Di Barbiano 1/10 Bologna 40136 Italy

E-mail: e.kon@biomec.ior.it 
This article has been cited by:

1. Peter J. Yang , Johnna S. Temenoff . Engineering Orthopedic Tissue InterfacesEngineering Orthopedic Tissue Interfaces. Tissue Engineering Part B: Reviews, ahead of print. [Abstract] [PDF] [PDF Plus] 